\title{
Synthesis and Highly Stable $\beta$-Sheet Formation of Sequential Alternating Amphiphilic Polypeptides
}

\author{
Yasumasa FuKushima \\ Research \& Development Center, Unitika Ltd., 23 Kozakura, Uji, Kyoto 611, Japan
}

(Received March 29, 1995)

\begin{abstract}
Alternating amphiphilic copolypeptides poly(Glu-Val-Lys-Val) and poly(Glu-Leu-Lys-Leu) were obtained by syntheses and polymerizations of the respective tetrapeptides and conformations were determined by circular dichroism measurements. The polypeptides reveal a very strong tendency to adopt the $\beta$-sheet conformation in aqueous solution even at various $\mathrm{pH}$ as well as in the presence of $1 \mathrm{M} \mathrm{NaCl}, 6 \mathrm{M}$ guanidine hydrochloride or $6 \mathrm{M}$ urea. The $\beta$-sheet structures also show thermal stability and independence of polypeptide concentrations. The high stability of $\beta$-sheet structures could be responsible for electrostatic interactions in addition to hydrophobic interactions and conventional $\beta$-sheet hydrogen bondings. It is presumed that two polypeptides form monomeric $\beta$-sheet structures by intramolecular interactions. These highly stable $\beta$-sheet forming polypeptides should provide good models for contributing hydrophobic and electrostatic interactions to the $\beta$-sheet structural formation in proteins, constructing de novo designed proteins and peptides involving $\beta$-sheet structures and studying the mechanism of $\beta$-protein folding.

KEY WORDS Alternating Amphiphilic Polypeptides / Stable $\beta$-Sheet Formation / Monomeric $\beta$-Sheet Structure / Complementary Ionic Interaction/ Hydrophobic Interaction /
\end{abstract}

The $\beta$-sheet conformation is an essential structural motif for many biologically active peptides and proteins. Polypeptides consisting of alternating hydrophilic and hydrophobic amino acid residues tend to form stable $\beta$-sheet conformations with hydrophobic interior and hydrophilic exterior in aqueous solution in the presence of salt and prolonged incubation due to the formation of mainly hydrophobic interaction. ${ }^{1}$ It was previously shown that the formation of $\beta$-sheet structures was dependent on $\mathrm{pH}$ and ionic strength in aqueous solutions for poly(Ala-Glu), poly(Val-Lys), poly(Leu-Lys), poly(Phe-Lys), poly(Tyr-Lys), and poly(Tyr-Glu). ${ }^{2-5}$ On the other hand, the corresponding random copolypeptides poly $\left(\mathrm{Phe}^{49}, \mathrm{Lys}^{51}\right)$ and poly $\left(\mathrm{Leu}^{50}{ }^{5}\right.$ Lys $\left.^{50}\right)$ showed $\alpha$ helical conformation under the same conditions. ${ }^{6,7}$

Several small alternating amphiphilic peptides have been designed to adopt stable $\beta$-sheet conformation in aqueous solution by specific inter-residue ion pair interactions between positively charged and negatively charged amino acid residues. ${ }^{8,9}$ These self-complementary ion pair interactions seem to form between side chains of amino acid residues separated by one residue $(i, i+2$ spacing) or three residues $(i, i+4$ spacing) in the sequence. In general, the enforced interactions appear to initiate the formation of local $\beta$-sheet conformation that propagates through the rest of the peptide chain. In particular, an alternating amphiphilic small peptide with complementary ion pair interaction is able to form $\beta$-sheet conformation in various $\mathrm{pHs}$ or in denaturation reagents such as $7 \mathrm{M}$ guanidine hydrogen chloride or $8 \mathrm{M}$ urea. In this case, it is likely that both intra- and intermolecular ionic complementary interactions exist for the unusual stabilization of the $\beta$-sheet conformation. ${ }^{10}$

In contrast, it has been reported that small amphiphilic peptides where glutamyl and lysine residues are positioned at $i$ and $i+4$ residues, respectively, exhibit stable $\alpha$-helical conformations due to the complementary salt bridges or ion pairs electrostatic interactions. ${ }^{11}$ The stability of the $\alpha$-helical conformations was affected by temperature, $\mathrm{pH}$ and ionic strength, but unaffected by peptide concentration. Consequently, $\alpha$-helical conformations were stabilized by intramolecular ionic complementary interactions, whereas the $\beta$-sheet structural conformations were stabilized by both intra- and intermolecular interactions.

In this study, we designed and synthesized sequential alternating amphiphilic polypeptides, poly(Glu-Val-LysVal-) and poly(Glu-Leu-Lys-Leu-), where ionic complementary interactions were introduced in order to form highly stable $\beta$-sheet structural conformations. The glutamic acids and lysines are separated by one residue in the sequence $(i, i+2$ spacing) to facilitate many potential complementary ion pair electrostatic interactions in the $\beta$-sheet structure. We selected valine and leucine residues as hydrophobic amino acid residues because a valine has the highest $\beta$-sheet structure forming propensity and a leucine has high hydrophobicity among naturally occurring amino acids. ${ }^{12}$ The conformation and $\beta$-sheet structural stability of the polypeptides were studied by circular dichroism in aqueous solution of varying $\mathrm{pH}$, peptide concentration, ionic strength, temperature and denaturation reagents. This paper describes the effects of the ionic complementary interactions and hydrophobic amino acid residues on the stabilization of $\beta$-sheet structural conformations.

\section{EXPERIMENTAL}

\section{Materials and Methods}

Boc-Glu(OBzl)-OH and Boc-Lys(Z)-OH were purchased from Peptide Institute, Inc. All other reagents and solvents were of high purity commercially available and were used without further purification. Dialysis membranes VT351, having a molecular weight cutoff of 3500, was from Nacalai. NMR spectra were obtained at $300 \mathrm{MHz}$ with a Varian VXR300.

The amino acid composition of the polypeptides was determined with a Hitachi 835 amino acid analyzer. The 
samples were hydrolyzed in evacuated, sealed tubes with $6 \mathrm{~N}$ hydrogen chloride at $110^{\circ} \mathrm{C}$ for $24 \mathrm{~h}$. The hydrolyzed polypeptides were derivatized by using ninhydrin.

\section{Molecular Weight Determination}

Viscosity and size exclusion chromatography methods were used in determining molecular weights of the polypeptides.

If we assume viscosity-molecular weight relationships studied by Doty, and obtained in the case of poly(benzyl-L-glutamate) in dichloroacetic acid, to be valid in our case also, we can estimate the order of the molecular weights of polypeptides by measuring the intrinsic viscosity in dichloroacetic acid with a ubbelohde capillary viscometer at $25^{\circ} \mathrm{C} .^{13}$ The intrinsic viscosity $[\eta]$ was determined by graphically extrapolating plots of $\left(\eta_{\mathrm{r}}-1\right) / c v s$. $c$, constructed from measurements at four concentrations. The symbol $\eta_{\mathrm{r}}$ stands for the ratio viscosities of the solution and solvent.

Size exclusion chromatography of the polypeptides was carried out by using a combination of $0.74 \mathrm{~cm}$ by $30 \mathrm{~cm}$ Ultrahydrogel 250 and $0.74 \mathrm{~cm}$ by $30 \mathrm{~cm}$ Ultrahydrogel 500 columns (Waters). The eluent was monitored by measuring absorbance at $214 \mathrm{~nm}$. The polypeptides or protein standards were applied to the column in $0.15 \mathrm{M}$ $\mathrm{NaCl}, 0.2 \mathrm{M}$ phosphate buffer, $\mathrm{pH} 7.0$, and eluted with the same buffer at a flow rate of $1.0 \mathrm{ml} \mathrm{min}^{-1}$. The polypeptides were applied to the column at a concentration of approximately $850 \mu \mathrm{M}$. Apparent molecular weight was determined by interpolation from the standard curve.

\section{Circular Dichroism (CD) Measurements}

$\mathrm{CD}$ spectra were obtained under a constant flow of nitrogen on a Jovin Ivon CD6 spectropolarimeter equipped with an interface and personal computer using a quartz cuvette of $1 \mathrm{~mm}$ pathlength. The instruments were calibrated with an aqueous solution of ammonium $d$-camphorsulfate. ${ }^{14}$ Polypeptides stock solutions were prepared at a concentration of approximately $3 \mathrm{mg} \mathrm{ml}^{-1}$ in distilled deionized water. The precise polypeptide concentration of the stock solutions was determined by ninhydrin analysis of a hydrolyzed polypeptide sample. $\mathrm{CD}$ samples were prepared by diluting the stock solutions either in water, various $\mathrm{pH}$ solutions, different concentrations of $5 \mathrm{M} \mathrm{NaCl}, 8 \mathrm{M}$ guanidine hydrochloric acid, or $10 \mathrm{M}$ urea. $\mathrm{pH}$ was measured with a Horiba $\mathrm{pH}$ meter F-16 before the CD measurements. The observed ellipticity was expressed as mean residue ellipticity $[\theta]$, which was normalized to units of degrees centimeter squared per decimole. The content of $\beta$-sheet structure was calculated on the basis of reported values of molar ellipticities of $100 \% \beta$-sheet polypeptide, $[\theta](217 \mathrm{~nm})=$

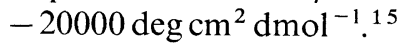

\section{Peptide Synthesis}

The syntheses of poly(Glu-Val-Lys-Val) and poly(GluLeu-Lys-Leu) are summarized in Scheme 1.

$N$ - $\alpha$-tert-Butoxycarbonyl- $\gamma$-benzyl-L-glutamyl-L-valine (I)

To L-valine $(1.17 \mathrm{~g}, 10.0 \mathrm{mmol})$ and sodium bicarbonate $(1.68 \mathrm{~g}, 20.0 \mathrm{mmol})$ dissolved in $30 \mathrm{ml}$ of water was added $N$-hydroxysuccinimide ester of Boc-Glu( $\gamma \mathrm{OBzl})$ -
$\mathrm{OH}(4.30 \mathrm{~g}, 10.0 \mathrm{mmol})$ in $60 \mathrm{ml}$ of dry tetrahydrofuran (THF). ${ }^{16}$ After $2 \mathrm{~h}$ of stirring at room temperature, the solution was concentrated, acidified with $0.5 \mathrm{~N}$ hydrochloric acid, and extracted with ethyl acetate. The organic layer was dried over anhydrous sodium sulfate, filtered and concentrated to give an oily product. The residual oil was washed with petroleum ether and ether by decantation to give $4.09 \mathrm{~g}(94.0 \%)$ of $\mathbf{I}$ as an oil.

\section{$N$ - $\alpha$-tert-Butoxycarbonyl- $N$-e-benzyloxycarbonyl-L-lysyl- L-valine (II)}

To aqueous solution $(60 \mathrm{ml})$ of $\mathrm{L}$-valine $(0.94 \mathrm{~g}, 8.0$ $\mathrm{mmol})$ and sodium bicarbonate $(1.34 \mathrm{~g}, 16.0 \mathrm{mmol})$ was added $N$-hydroxysuccinimide ester of Boc-Lys(Z)-OH $(2.00 \mathrm{~g}, 8.0 \mathrm{mmol})$ in $80 \mathrm{ml}$ of dry THF at room temperature. ${ }^{17}$ After the solution was stirred for $5 \mathrm{~h}$, the reaction mixture was treated as described above for the preparation of I to give an oily product. The residual oil was washed with petroleum ether and ether to obtain $3.24 \mathrm{~g}(84.6 \%)$ of II as an oil.

$N$ - $\alpha$-tert-Butoxycarbonyl- $\gamma$-benzyl-L-glutamyl-L-valyl- $N$ $\varepsilon$-benzyloxycarbonyl-L-lysyl-L-valine (III)

To a solution of Compound I $(2.60 \mathrm{~g}, 6.05 \mathrm{mmol})$ and $N$-hydroxysuccinimide $(0.77 \mathrm{~g}, 6.65 \mathrm{mmol})$ in THF $(80 \mathrm{ml})$ was added $N, N^{\prime}$-dicyclohexylcarbodiimide (DCC, $1.37 \mathrm{~g}, 6.65 \mathrm{mmol})$ at $0^{\circ} \mathrm{C}$. After $20 \mathrm{~h}$ of stirring, the insoluble dicyclohexylurea was filtered off, the filtrate was washed with $0.5 \mathrm{M}$ sodium bicarbonate, $0.5 \mathrm{~N}$ hydrochloric acid and water successively, dried over anhydrous sodium sulfate, and concentrated under reduced pressure. The residual oil was crystallized from 2-propanol. Recrystallization from 2-propanol gave $2.55 \mathrm{~g}(4.84 \mathrm{mmol}, 80.0 \%)$ of Boc-Glu( $\gamma \mathrm{OBzl})-\mathrm{Val}-\mathrm{OSu}$.

Compound II $(2.30 \mathrm{~g}, 4.84 \mathrm{mmol})$ was dissolved in trifluoroacetic acid (TFA) and the solution was stirred at room temperature for $1 \mathrm{~h}$. TFA was removed in vacuo and the residual oily product was triturated with ether and dried in vacuo. To the precipitate and sodium bicarbonate $(1.62 \mathrm{~g}, 19.3 \mathrm{mmol})$ dissolved in $40 \mathrm{ml}$ of a mixture of water-tetrahydrofuran (THF) (1:1) was
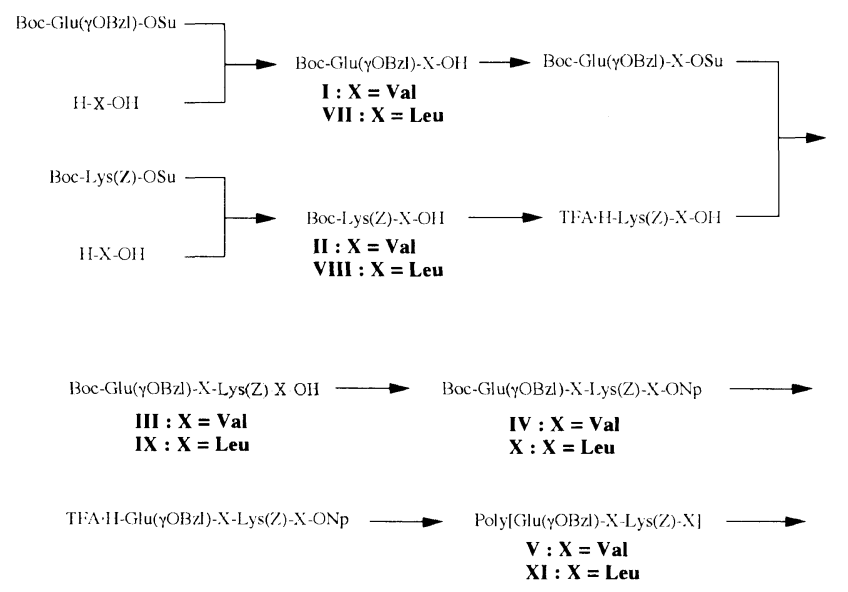

Poly[Glu-X-Lys-X]

VI $: X=$ Val
XII $: X=$ Leu

Scheme 1. Synthetic routes of poly(Glu-Val-Lys-Val) and poly(GluLeu-Lys-Leu): OBzl, benzyl ester; Z, benzyloxycarbonyl; OSu, $N$ hydroxysuccinimide ester; Boc, tert-butyloxycarbonyl; ONp, p-nitrophenyl ester; TFA, trifluoroacetic acid.

Polym. J., Vol. 28, No. 2, 1996 
added Boc-Glu( $\gamma \mathrm{OBzl})-\mathrm{Val}-\mathrm{OSu}$ in $40 \mathrm{ml}$ of THF. After $20 \mathrm{~h}$ of stirring at room temperature, the reaction mixture was treated as described above for the preparation of $\mathbf{I}$ to give an oily product. The oil was solidified with petroleum ether and ether to obtain $2.53 \mathrm{~g}(62.1 \%)$ of III. Elemental Analysis. Found: C=61.93\%; $\mathrm{H}=7.38 \%$; $\mathrm{N}=8.56 \%$. Calcd for $\mathrm{C}_{41} \mathrm{H}_{59} \mathrm{O}_{11} \mathrm{~N}_{5}: \quad \mathrm{C}=61.72 \%$; $\mathrm{H}=7.45 \% ; \mathrm{N}=8.78 \%$.

$N$ - $\alpha$-tert-Butoxycarbonyl- $\gamma$-benzyl-L-glutamyl-L-valyl$N$ - $\varepsilon$-benzyloxycarbonyl-L-lysyl-L-valine p-Nitrophenyl Ester (IV)

A solution of compound III $(2.00 \mathrm{~g}, 2.53 \mathrm{mmol})$ and p-nitrophenol (HO-Np, $0.39 \mathrm{~g}, 2.78 \mathrm{mmol}$ ) in $30 \mathrm{ml}$ of THF was treated with DCC $(0.57 \mathrm{~g}, 2.78 \mathrm{mmol})$ at $0^{\circ} \mathrm{C}$ for $20 \mathrm{~h}$ with stirring. The produced dicyclohexylurea was filtered off and the filtrate was evaporated in vacuo to give an oily product. The oil was triturated with ether and petroleum ether to obtain $1.42 \mathrm{~g}(61.5 \%)$ of IV. NMR spectrum shows the appearance of the signals assigned to $p$-nitrophenyl group after activating reaction at the carboxylic terminal. Elemental Analysis. Found: $\mathrm{C}=$ $61.37 \% ; \mathrm{H}=6.87 \% ; \mathrm{N}=9.01 \%$. Calcd for $\mathrm{C}_{47} \mathrm{H}_{62} \mathrm{O}_{13^{-}}$ $\mathrm{N}_{6}: \mathrm{C}=61.43 \% ; \mathrm{H}=6.80 \% ; \mathrm{N}=9.14 \%$.

\section{Poly( $\gamma$-benzyl-L-glutamyl-L-valyl-N-E-benzyloxycarbonyl- L-lysyl-L-valine) (V) \\ To compound IV $(1.27 \mathrm{~g}, 1.39 \mathrm{mmol})$ was added TFA} $(3 \mathrm{ml})$ and the mixture was stirred at room temperature for $1 \mathrm{~h}$. After evaporation of TFA in vacuo, trituration with ether gave a white precipitate. To the solution of the product in $0.8 \mathrm{ml}$ of dimethylsulfoxide (DMSO) was added triethylamine $(0.29 \mathrm{ml}, 2.08 \mathrm{mmol})$. The reaction mixture was stirred at room temperature to become very viscous within 2 days. After standing the mixture at room temperature for more than a week, the mixture was triturated with ether. The precipitate was washed with water, methanol and ether to obtain $0.772 \mathrm{~g}(82.4 \%)$ of V. NMR spectrum show the disappearance of the signals assigned to $p$-nitrophenyl group after the polymerization reaction.

\section{Poly(L-glutamyl-L-valyl-L-lysyl-L-valine) (VI)}

Compound $\mathbf{V}(0.221 \mathrm{~g}, 0.329 \mathrm{mmol})$ was treated with methanesulfonic acid $(2 \mathrm{ml})$ in the presence of anisole $(0.2 \mathrm{ml})$ at room temperature for $1 \mathrm{~h}$ and the mixture was triturated with ether to give a white precipitate. The solid was washed with methanol and ether and dried. The powder was dissolved in water $(20 \mathrm{ml})$ and the solution filtered through a $0.45 \mu \mathrm{m}$ Millipore filter. The solution was dialyzed against 1 liter of deionized distilled water for a week (the water was changed once a day) and lyophilized to obtain $0.113 \mathrm{~g}(76.5 \%)$ of VI. ${ }^{1} \mathrm{H}$ NMR of poly[Glu-Val $\left.-\mathrm{Lys}_{1}-\mathrm{Val}_{2}\right](\delta$, ppm from TMS in HFIP- $\left.d_{2}\right): 0.85-1.20\left(12 \mathrm{H}, 4 \times \gamma \mathrm{CH}_{3}\right.$ in $\mathrm{Val}_{1}$ and $\left.\mathrm{Val}_{2}\right)$, $1.42-1.67\left(2 \mathrm{H}, \gamma \mathrm{CH}_{2}\right.$ in Lys), $1.71-1.88\left(4 \mathrm{H}, \beta \mathrm{CH}_{2}\right.$ and $\delta \mathrm{CH}_{2}$ in Lys), $1.91-2.04\left(2 \mathrm{H}, \beta \mathrm{CH}_{2}\right.$ in $\left.\mathrm{Glu}\right)$, $2.05-2.26\left(2 \mathrm{H}, 2 \times \beta \mathrm{CH}\right.$ in $\mathrm{Val}_{1}$ and $\left.\mathrm{Val}_{2}\right), 2.32-2.56$ $\left(2 \mathrm{H}, \gamma \mathrm{CH}_{2}\right.$ in Glu), $3.10-3.23\left(2 \mathrm{H}, \varepsilon \mathrm{CH}_{2}\right.$ in Lys), $3.93-4.24\left(4 \mathrm{H}, \alpha \mathrm{CH}\right.$ in Glu, $\mathrm{Val}_{1}, \mathrm{Val}_{2}$, and Lys). All NMR signals were broadened. NMR spectra show the disappearance of signals assigned to $\mathrm{OBzl}$ and $\mathrm{Z}$ groups after the cleavage reaction of these protecting groups with methanesulfonic acid in the presence of anisole. The amino acid ratios found were $\mathrm{Glu}_{1.04} \mathrm{Val}_{1.92} \mathrm{Lys}_{0.87}$.

\section{Poly(L-glutamyl-L-leucyl-L-lysyl-L-leucine) (XII)}

Compound XII was synthesized in a $17.8 \%$ total yield via preparations from compound VII to XI in analogy with the synthesis of poly(Glu-Val-Lys-Val). ${ }^{1} \mathrm{H}$ NMR of poly[Glu-Leu -Lys-Leu $\left._{2}\right](\delta$, ppm from TMS in HFIP- $\left.d_{2}\right): 0.90-1.09\left(12 \mathrm{H}, 4 \times \delta \mathrm{CH}_{3}\right.$ in $\mathrm{Leu}_{1}$ and $\left.\mathrm{Leu}_{2}\right)$, $1.45-1.90\left(10 \mathrm{H}, \gamma \mathrm{CH}_{2}\right.$ and $\delta \mathrm{CH}_{2}$ in Lys, and $2 \times \beta \mathrm{CH}_{2}$ and $2 \times \gamma \mathrm{CH}$ in $\mathrm{Leu}_{1}$ and $\left.\mathrm{Leu}_{2}\right), 1.91-2.08\left(2 \mathrm{H}, \beta \mathrm{CH}_{2}\right.$ in Lys), $2.11-2.32\left(2 \mathrm{H}, \beta \mathrm{CH}_{2}\right.$ in Glu $), 2.41-2.65(2 \mathrm{H}$, $\gamma \mathrm{CH}_{2}$ in Glu), $3.10-3.24\left(2 \mathrm{H}, \varepsilon_{2} \mathrm{CH}_{2}\right.$ in Lys $), 4.10-4.41$ $\left(4 \mathrm{H}, \alpha \mathrm{CH}\right.$ in Glu, and $2 \times \alpha \mathrm{CH}$ in $\mathrm{Leu}_{1}$ and $\mathrm{Leu}_{2}$, and $\alpha \mathrm{CH}$ in Lys). All NMR signals were broadened. The amino acid ratios found were $\mathrm{Glu}_{1.07} \mathrm{Leu}_{2.07} \mathrm{Lys}_{0.86}$.

\section{RESULTS}

\section{Polypeptide Synthesis}

The $\alpha$-amino and $\gamma$-carboxyl groups of Glu were protected with $t$-butyloxycarbonyl (Boc) and benzyl (Bzl) groups, respectively. The $\alpha$-amino and $\varepsilon$-amino groups of Lys were protected with Boc and benzyloxycarbonyl (Z) groups, respectively. The Boc group was selectively removed by anhydrous trifluoroacetic acid, while the Bzl and $\mathrm{Z}$ groups were eliminated after completion of the polypeptide synthesis by treatment with methanesulfonic acid in the presence of anisole. ${ }^{18}$ Each of the two tetrapeptide monomers was synthesized similarly in stepwise manner, adding Boc amino acid $N$-hydroxysuccinimide active esters to a growing carboxyl-terminal residue with a free amino group. Dicyclohexylcarbodiimide was used for the synthesis of the $N$-hydroxysuccinimide active esters, colorless crystalline derivatives, with good stability.

The polymerization of sequential polypeptides having a defined repeating unit of amino acids is usually achieved by self-condensation of monomer peptide active esters. Among the $p$-nitrophenyl-, pentachlorophenyl-, and $N$-hydroxysuccinimide esters, the most widely used active esters, we selected $p$-nitrophenyl esters for good solubility. High solubility of the peptide active ester was essential to synthesize polypeptides with high molecular weights, because the preparation of a satisfactory concentrated solution of activated monomers can avoid intramolecular cyclization during polymerization. ${ }^{19,20}$ The polymerization was carried out in dimethylsulfoxide solution in the presence of triethylamine.

The synthetic strategy was as follows in order to minimize racemization. Boc was used as much as possible because it was a protecting group which depresses racemization to a great extent. ${ }^{21}$ In the coupling reactions, the corresponding $N$-hydroxysuccinimide active esters were used because of their high reactivity and relatively low racemization during coupling. ${ }^{22}$ In polymerization reactions, the corresponding $p$-nitrophenyl active esters were utilized due to their high reactivity. The active esters were synthesized on cooling with ice because this reaction was exothermic. It must be kept in mind that triethylamine was required as a highly pure base without primary and secondary amines and its excess addition was avoided in polymerization reactions. 
Poly(Glu-Val-Lys-Val) showed an intrinsic viscosity of $0.114 \mathrm{dl} \mathrm{g}^{-1}$ in dichloroacetic acid which is a random-coil forming solvent for polypeptides. The intrinsic viscosity value corresponds to a molecular weight of 14000 if we apply eq 1 proposed by Doty et al. ${ }^{13}$

$$
[\eta]=2.78 \times 10^{-5} \mathrm{M}^{0.87}
$$

Figure 1 illustrates the calibration curve for the column and size exclusion chromatography profile for both polypeptides. Size exclusion chromatogram showed that poly(Glu-Val-Lys-Val) was eluted into one fraction at the elution time corresponding to a molecular weight of 14400 with 2.69 of molecular weight distribution, and no additional fraction was observed in the exclusion limit or low molecular weight regions. Both molecular weights gave excellent agreement. On the other hand, an intrinsic viscosity value for poly(Glu-Leu-Lys-Leu) in dichloroacetic acid is $0.127 \mathrm{dl} \mathrm{g}^{-1}$, which corresponds to a molecular weight 16000 . For poly(Glu-Leu-Lys-Leu), a size exclusion chromatogram showed molecular weight distribution is 2.90 and molecular weight is 18400 , and no additional fraction was observed in analogy with poly(Glu-Val-Lys-Val). The molecular weight is in fair agreement with that determined from the intrinsic viscosity value.

Under the conditions of the viscosity measurements, the polypeptides appear to exist as a random-coil monomeric state in dilute solution of dichloroacetic

(A)
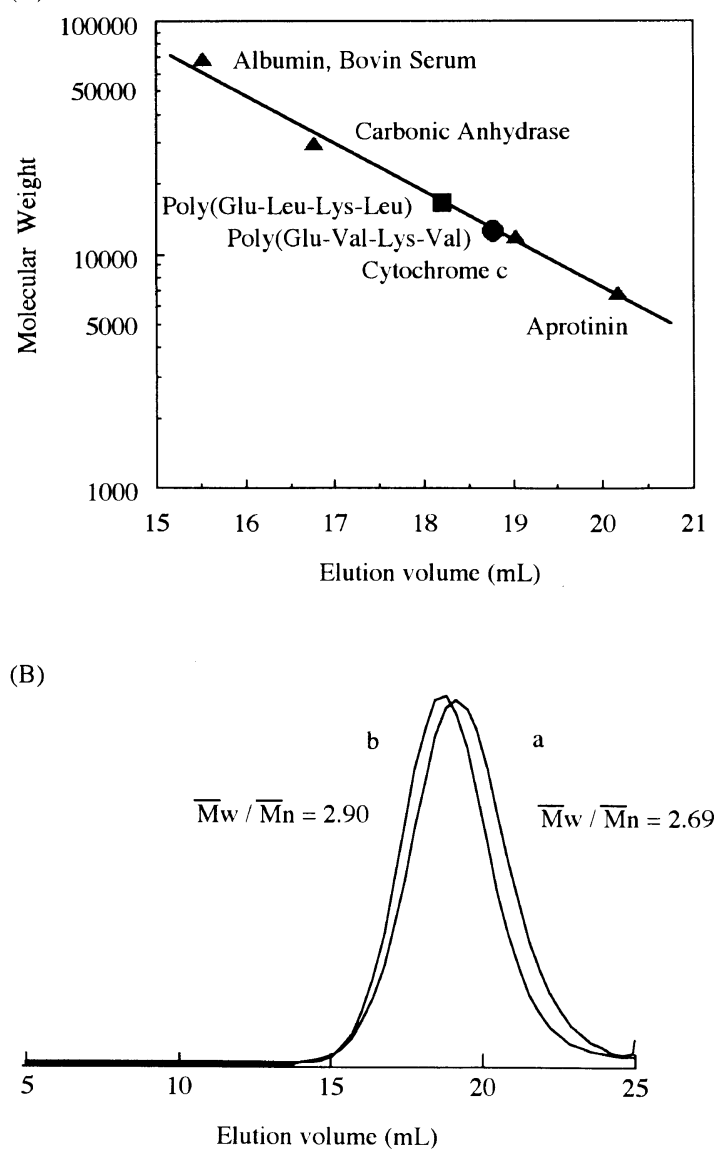

Figure 1. (A) Calibration curve for a combination of a $0.78 \times 30 \mathrm{~cm}$ Ultrahydrogel 250 and a $0.78 \times 30 \mathrm{~cm}$ Ultrahydrogel 500 columns used in the size exclusion chromatography of the polypeptides. (O) poly(Glu-Val-Lys-Val); (ם) poly(Glu-Leu-Lys-Leu). (B) SEC profile of the polypeptides. a, poly(Glu-Val-Lys-Val); b, poly(Glu-Leu-Lys-Leu). acid. The polypeptides form $\beta$-sheet structures under the conditions of the size exclusion chromatography measurements. Therefore, for both polypeptides, these $\beta$-sheet structures appear to exist as a monomeric polypeptide because the molecular weight estimated from the intrinsic viscosity is in accord with that from size exclusion chromatography. These $\beta$-sheet structures are stabilized by intramolecular interactions such as conventional $\beta$-sheet hydrogen bondings.

\section{Dependence of $\beta$-Sheet Formation on $p H$}

The secondary structures of these polypeptides are readily characterized by circular dichroism (CD) spectroscopy. CD spectra of poly(Glu-Val-Lys-Val) in aqueous solution at different $\mathrm{pH}$ are shown in Figure 2. All the CD spectra have characteristic a minimum around $217 \mathrm{~nm}\left(\mathrm{n}-\pi^{*}\right.$ transition) and maximum around $197 \mathrm{~nm}$ ( $\pi-\pi^{*}$ transition), which indicates that the polypeptide exists in a predominantly $\beta$-sheet conformation at all experimental pHs. ${ }^{15}$ The extent of $\beta$-sheet formation is most easily monitored by following the intensity of the ellipticity at $217 \mathrm{~nm}$. The ellipticity at $217 \mathrm{~nm}$ varies from 14800 to $11000 \mathrm{deg} \mathrm{cm} \mathrm{dmol}^{-1}$. The $\beta$-sheet contents at pH 7.0 and pH 2.0 or $\mathrm{pH} 12.0$ are approximately $75 \%$ and $55 \%$, respectively. CD spectra taken through the transition show an isodichroic point at $207 \mathrm{~nm}$, which is consistent with two-state transition with each residue being in either a $\beta$-sheet or random-coil conformation. These data demonstrate that the polypeptides undergo a broad conformational transition from the random-coil to the $\beta$-sheet structure induced by changing acidic or alkaline $\mathrm{pH}$ to neutral $\mathrm{pH}$.

In analogy with poly(Glu-Val-Lys-Val), poly(GluLeu-Lys-Leu) adopts a $\beta$-sheet conformation from $\mathrm{pH}$ 2.0 to $\mathrm{pH} 12.0$ by the characterization of $\mathrm{CD}$ spectra shown in Figure 3. $\beta$-Sheet contents at both $\mathrm{pH}$ extremes are $75 \%$, and increase to $90 \%$ at neutral $\mathrm{pH}$. Lysine is a positively charged residue and glutamic acid is a negatively charged residue. Lysine residue has a $\mathrm{p} K_{\mathrm{a}}$ of 10.0 and glutamic acid residue has a $\mathrm{p} K_{\mathrm{a}}$ of 4.4 in proteins. The polypeptides contain both lysine and glutamic acid residues. Therefore the conformation of the polypeptides is anticipated to be affected by $\mathrm{pH}$ changes. $\beta$-sheet

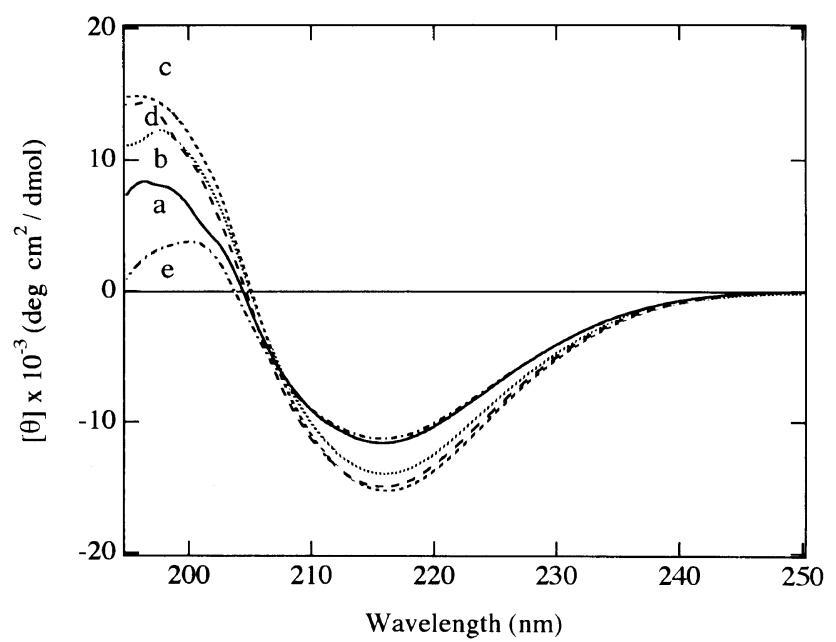

Figure 2. CD spectra of poly(Glu-Val-Lys-Val) at $526 \mu \mathrm{M}$ in aqueous solution at different pH values. pH values: (a) 2.0; (b) 4.0; (c) 7.0; (d) 10.0 ; (e) 12.0 


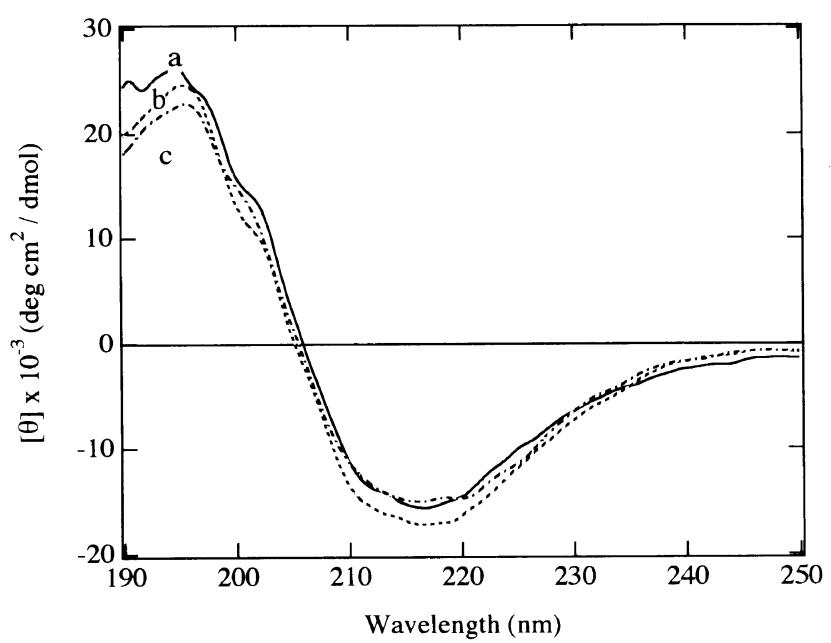

Figure 3. CD spectra of poly(Glu-Leu-Lys-Leu) at $526 \mu \mathrm{M}$ in aqueous solution at different $\mathrm{pH}$ values. $\mathrm{pH}$ values: (a) 2.0 ; (b) 7.0 ; (c) 12.0 .

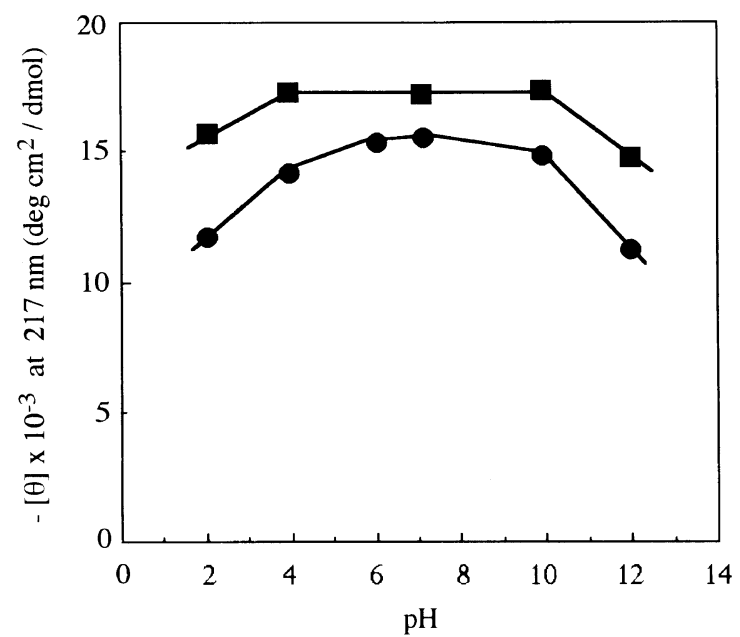

Figure 4. Dependence of $\beta$-sheet content on $\mathrm{pH}$ for two amphiphilic polypeptides. (O) poly(Glu-Val-Lys-Val); ( $\mathbf{\square}$ ) poly(Glu-Leu-Lys-Leu).

conformations for both polypeptides are affected slightly by $\mathrm{pH}$ changes. Figure 4 shows the $\mathrm{pH}$ dependences of the ellipticity at $217 \mathrm{~nm}$ both for the polypeptides. Both curves are bell-shaped. In both polypeptides, the $\beta$-sheet conformation is most stable at neutral $\mathrm{pH}$, where lysine and glutamic acid residues are ionized. However, the $\beta$-sheet contents decrease at both extreme $\mathrm{pHs}$, where lysine or glutamic acid residues are uncharged. The $\beta$-sheet formation for poly(Glu-Leu-Lys-Leu) is affected less than that for poly(Glu-Val-Lys-Val) by $\mathrm{pH}$ change. In addition, the $\beta$-sheet contents of poly(Glu-Leu-LysLeu) are higher than those of poly(Glu-Val-Lys-Val) at all experimental $\mathrm{pHs}$. These results indicate that $\beta$-sheet stability for poly(Glu-Leu-Lys-Leu) is superior to that for poly(Glu-Val-Lys-Val) against $\mathrm{pH}$ change. Both these polypeptides form a very stable $\beta$-sheet structure essentially unchanged in all experimental pHs aqueous solution. On the other hand, poly(Lys-Val) and poly(LysLeu) adopt $\beta$-sheet structure in aqueous solution in the presence of salt, but the secondary structures were dependent on $\mathrm{pH}^{3}$

\section{Dependence of $\beta$-Sheet Formation on Polypeptide Concentration}

A typical $\beta$-sheet CD profile was obtained in $\mathrm{pH} 7.0$

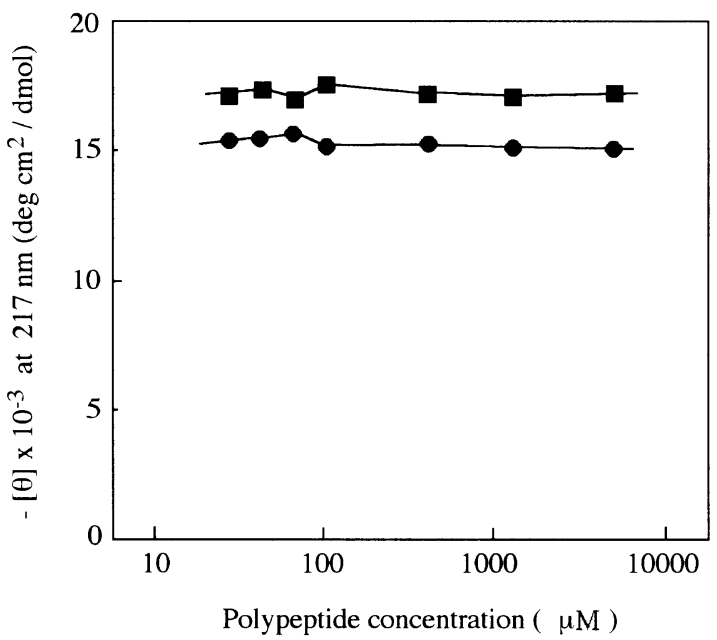

Figure 5. Dependence of $\beta$-sheet content on polypeptide concentration for two amphiphilic polypeptides. (O) poly(Glu-Val-Lys-Val); ( poly(Glu-Leu-Lys-Leu).

aqueous solution of each the polypeptide at polypeptide concentration from 26.3 to $5260 \mu \mathrm{M}$ (data not shown). Even at the lowest measurable polypeptide concentration $(26.3 \mu \mathrm{M})$ for both polypeptides, CD spectrum showed $\beta$-sheet formation. Figure 5 shows the dependence of ellipticity at $217 \mathrm{~nm}$ on polypeptide concentrations for both polypeptides. Under these conditions, the ellipticities of poly(Glu-Val-Lys-Val) and poly(Glu-Leu-LysLeu) at $217 \mathrm{~nm}$ were held almost constant at approximately 15000 and $18000 \mathrm{deg} \mathrm{cm}^{2} \mathrm{dmol}^{-1}$, respectively. These values correspond to $75 \%$ and $90 \%$ of $\beta$-sheet content, respectively. These results suggest that both polypeptides form a stable $\beta$-sheet structure in very dilute solution.

The independence of $\mathrm{CD}$ signal indicates that the $\beta$-sheet forming unit is monomeric or the lowest measurable polypeptide concentration has not attained the concentration required to dissociate an aggregated $\beta$-sheet structure. In these cases, the polypeptides seem to adopt monomeric $\beta$-sheet structures from the agreement of molecular weights by the two methods. These polypeptides can bend back on themselves to form monomeric $\beta$-sheet structures as seen in some natural proteins because both polypeptides have high molecular weights. The intramolecular $\beta$-sheet assembled structures can be stabilized by intramolecular hydrophobic interactions between leucine residues as well as electrostatic interactions between lysine and glutamic acid residues in addition to conventional $\beta$-sheet hydrogen bondings. It can therefore be presumed that these polypeptides form monomeric $\beta$-sheet structures.

Dependence of $\beta$-Sheet Formation on Salt Concentration

Figure 6 shows dependencies of ellipticity at $217 \mathrm{~nm}$ on $\mathrm{NaCl}$ concentration for both polypeptides. These ellipticities remain almost constant through $1 \mathrm{M}$ of the $\mathrm{NaCl}$ concentration. Therefore, both polypeptides form stably $\beta$-sheet structure in the presence of monovalent inorganic salt which can screen charge-charge interactions such as hydrogen bondings and ionic interactions by mobile counterions. Furthermore, there is no difference of stability between the polypeptides with the addition of salt. 


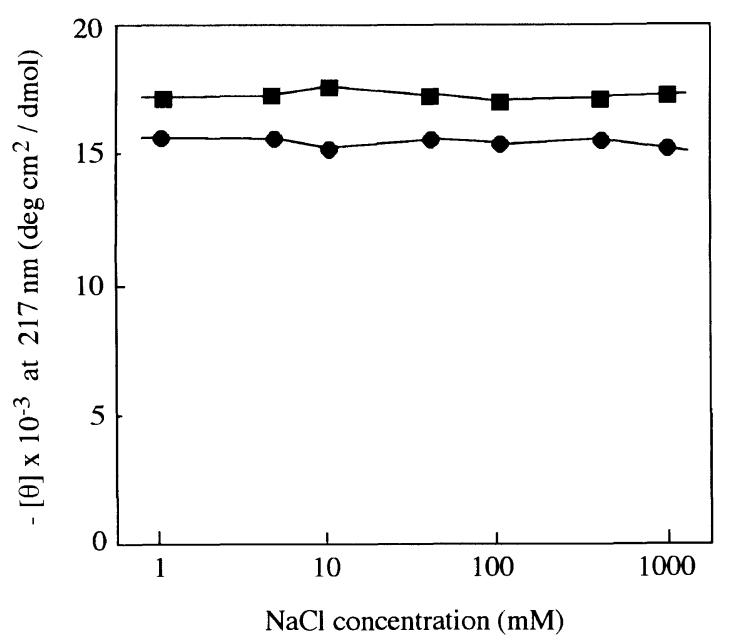

Figure 6. Dependence of $\beta$-sheet content on $\mathrm{NaCl}$ concentration for two amphiphilic polypeptides. (O) poly(Glu-Val-Lys-Val); ( $\square$ ) poly(Glu-Leu-Lys-Leu).

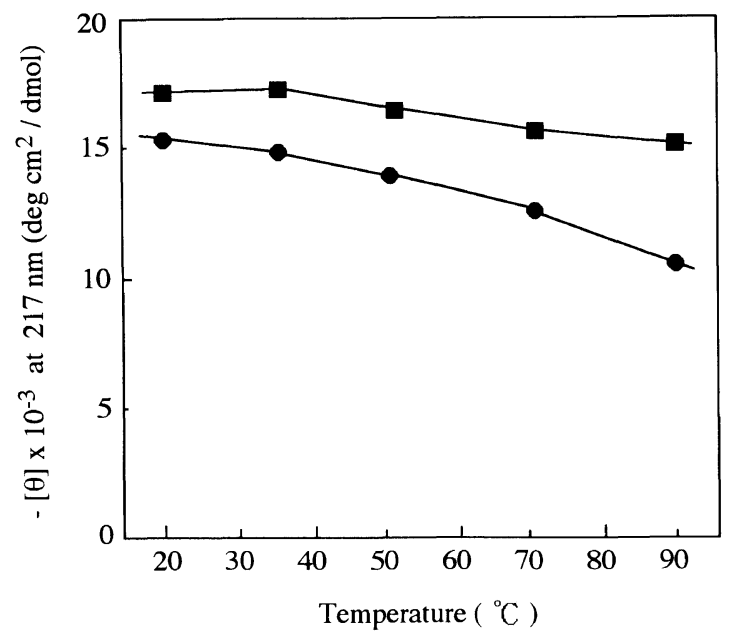

Figure 7. Dependence of $\beta$-sheet content on temperature for two amphiphilic polypeptides. (O) poly(Glu-Val-Lys-Val); (ם) poly(GluLeu-Lys-Leu).

\section{Dependence of $\beta$-Sheet Formation on Temperature}

$\mathrm{CD}$ spectra were obtained in the temperature range from 20 to $90^{\circ} \mathrm{C}$ in $\mathrm{pH} 7.0$ aqueous solution for both poly(Glu-Val-Lys-Val) and poly(Glu-Leu-Lys-Leu). Both polypeptides adopted a $\beta$-sheet structure at all temperatures tested. Figure 7 shows the dependences of ellipticity at $217 \mathrm{~nm}$ on the measured temperature for these polypeptides. These ellipticities decrease with increasing temperature for both polypeptides. The decrease of $\beta$-sheet structural content is approximately $30 \%$ from 20 to $90^{\circ} \mathrm{C}$ in the case of poly(Glu-Val-LysVal), but almost $10 \%$ for poly(Glu-Leu-Lys-Leu). These results indicate that the $\beta$-sheet structures of these polypeptides are very thermally stable, and poly(GluLeu-Lys-Leu) is more thermally stable than the other polypeptide. On the other hand, $\alpha$-helical content decreased approximately $60 \%$ from 0 to $90^{\circ} \mathrm{C}$ in aqueous solution for unusually stable $\alpha$-helical bundle and $\alpha$ helical coiled-coil peptides. ${ }^{23,24}$

\section{Dependence of $\beta$-Sheet Formation on Denaturants}

Urea and guanidine hydrochloride are most generally utilized as denaturants of proteins and peptides. The

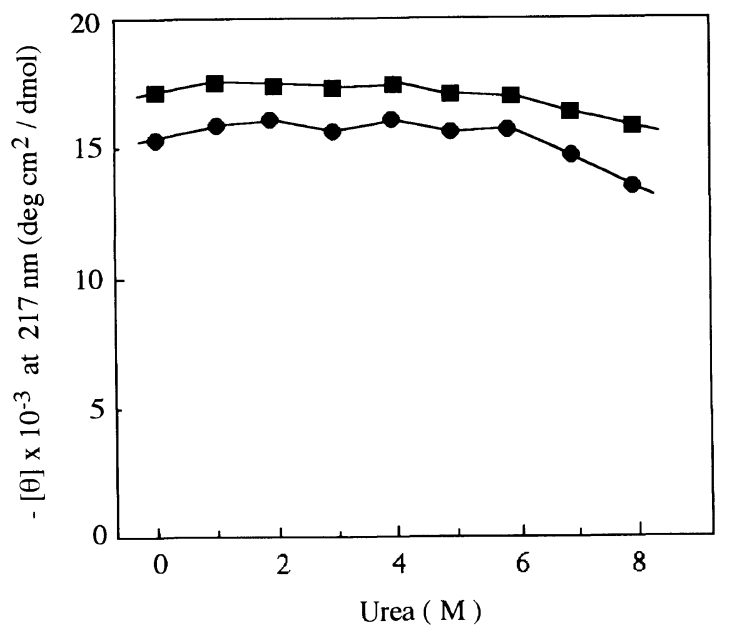

Figure 8. Dependence of $\beta$-sheet content on urea concentration for two amphiphilic polypeptides. ( $)$ poly(Glu-Val-Lys-Val); ( $\mathbf{\square})$ poly(Glu-Leu-Lys-Leu).

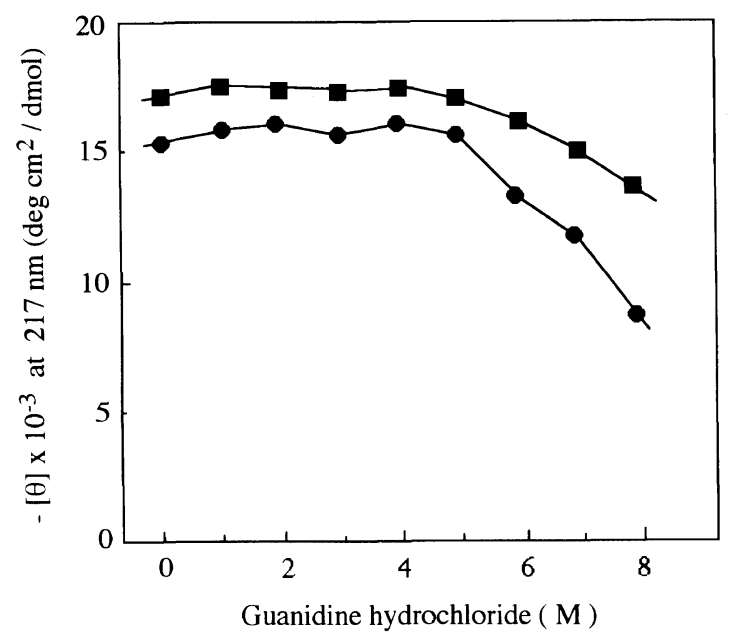

Figure 9. Dependence of $\beta$-sheet content on guanidine hydrochloride concentration for two amphiphilic polypeptides. (O) poly(Glu-ValLys-Val); (ם) poly(Glu-Leu-Lys-Leu).

effects of urea and guanidine hydrochloride as the denaturants on the stability of $\beta$-sheet structure for the polypeptides are shown in Figures 8 and 9, respectively. Figure 8 shows ellipticity at $217 \mathrm{~nm}$ for the polypeptides in the range of 0 to $8 \mathrm{M}$ of urea. The $\beta$-sheet structural content of poly(Glu-Leu-Lys-Leu) is not significantly affected by $8 \mathrm{M}$ urea, and the content of poly(Glu-ValLys-Val) decreases $90 \%$ from 0 to $8 \mathrm{M}$ urea.

Figure 9 shows the dependencies of the ellipticity at $217 \mathrm{~nm}$ for the polypeptides on guanidine hydrochloride concentration. The unfolding of $\beta$-sheet structure starts from approximately $5.5 \mathrm{M}$ guanidine hydrochloride. $\beta$-Sheet structural contents decrease almost $60 \%$ and $80 \%$ from 0 to $8 \mathrm{M}$ guanidine hydrochloride for poly(Glu-Val-Lys-Val) and poly(Glu-Leu-Lys-Leu), respectively.

\section{DISCUSSION}

\section{High $\beta$-Sheet Stability}

In general, alternating amphiphilic polypeptides form aggregated $\beta$-sheet structures under certain conditions in aqueous solution by intermolecular hydrophobic interac- 
tions. However, the $\beta$-sheet structure can be affected by $\mathrm{pH}$, ionic strength and the addition of denaturants. ${ }^{1-5}$ Poly(Glu-Val-Lys-Val) and poly(Glu-Leu-Lys-Leu), were obtained by introducing ion pairs or salt bridges, which form surprisingly stable $\beta$-sheet structures. These polypeptides could be stabilized by intramolecular electrostatic interactions between side chains of glutamic acid and lysine residues relative to alternating amphiphilic polypeptides such as poly(Lys-Val) and poly(Lys-Leu) reported previously. ${ }^{3}$ Under optimal $\beta$-sheet forming conditions, poly(Glu-Val-Lys-Val) and poly(Glu-LeuLys-Leu) show as much as $75 \%$ and $90 \% \quad \beta$-sheet structural content, respectively. The difference of $\beta$-sheet structural content is attributed to hydrophobicity of leucine and valine residues. Poly(Glu-Leu-Lys-Leu) is more stabilized than the other, because leucine residues are more hydrophobic than valine residues. Both hydrophobic and electrostatic interactions may play very important roles in the stabilization of $\beta$-sheet structures.

The ratios of Glu and Lys for poly(Glu-Val-Lys-Val) and poly(Glu-Leu-Lys-Leu) were 1.04:0.87 and 1.07: 0.86 , respectively. Although both ratios were not $1: 1$, they were approximately identical. These results suggest that the ratios may not affect a difference of CD spectra between the polypeptides, so the difference was due to difference of hydrophobicity between a valine and leucine residues.

For both polypeptides, $\beta$-sheet content decreases slightly by change in $\mathrm{pH}$ from neutral to acidic or alkaline conditions. The simplest explanation is that the hydrogen bonds persist when one partner of the salt bridge is uncharged and that the salt bridge $\left(\mathrm{Glu}^{-}--\mathrm{Lys}^{+}\right)$is more slightly effective than these singly charged hydrogen bonds (Glu--- $\mathrm{Lys}^{+}$at $\mathrm{pH}$ 2.0, Glu ${ }^{-}$--- Lys at $\mathrm{pH} 12.0$ ) in stabilizing the $\beta$-sheet structure if hydrophobic interaction is independent of $\mathrm{pH}$. On the other hand, poly(Lys-Val) and poly(Lys-Leu) cannot adopt $\beta$-sheet structure in all $\mathrm{pHs}$, while they form $\beta$-sheet structure in acidic solution in the presence of salt due to prevention of electrostatic repulsion between lysine residues. Therefore, there is a difference about $\beta$-sheet structural stability against $\mathrm{pH}$ between our polypeptides and poly(Lys-Val) or poly(Lys-Leu) because our polypeptides are stabilized by electrostatic and hydrophobic interactions, while poly(Lys-Val) and poly(Lys-Leu) are done by only hydrophobic interactions. Therefore, our polypeptides form unusually stable $\beta$-sheet structures not roughly dependent on $\mathrm{pH}$ by complementary ionic interactions.

The stability of $\beta$-sheet structures is not dependent on polypeptide concentration up to $26.3 \mu \mathrm{M}$ which is the lowest concentration measurable by a $\mathrm{CD}$ instrument for both polypeptides. The concentration independence indicates that the formation of secondary structures is generally an intramolecular event. The formation of monomeric $\beta$-sheet structures is supported by the results of viscosity and size exclusion chromatography measurements.

In spite of shielding of electrostatic interactions by mobile counterions, there is no significant change in $\beta$-sheet structural content in $\mathrm{pH} 7.0$ aqueous solution from 0 to $1 \mathrm{M} \mathrm{NaCl}$. The addition of $\mathrm{NaCl}$ decreases conventional $\beta$-sheet hydrogen bondings as well as electrostatic interactions because attractive interactions such as ion pairs, salt bridges or hydrogen bondings can be screened almost completely by $1 \mathrm{M} \mathrm{NaCl}$. In contrast, intramolecular hydrophobic interactions may increase by affecting the water structure with the addition of $\mathrm{NaCl}$. Therefore, these polypeptides form the stable $\beta$-sheet structures by compensation between the decreases of electrostatic interactions and increase of hydrophobic interactions.

The $\beta$-sheet structures in these polypeptides are weekly dependent on temperature. The $\beta$-sheet structures form with maximal $\beta$-sheet content at low temperature and unfolding occurs somewhat with increasing temperature. Because $\beta$-sheet formation is generally entropy-driven for alternating amphiphilic polypeptides and poly(GluLeu-Lys-Leu) is more thermally stable than the other, hydrophobic interactions seem to be an important factor in the thermal stability of the monomeric $\beta$-sheet structure if the electrostatic interactions between these polypeptides are equivalent. In addition to hydrophobic effects, there is the enthalpic contribution for ion pairs or salt bridge formation and conventional $\beta$-sheet hydrogen bondings in aqueous solution for stability.

In addition, these polypeptides are stable in denaturants as high as $8 \mathrm{M}$ urea and $5.5 \mathrm{M}$ guanidine hydrochloride, although these denaturants effectively denature other $\beta$-sheet structure forming proteins and peptides above $4 \mathrm{M}$.

These polypeptides formed the monomeric $\beta$-sheet structure immediately after preparation of samples under appropriate experimental conditions. In general, alternating amphiphilic polypeptides take an aggregated $\beta$ sheet structure after standing for several weeks or hours in aqueous solution in the presence of salt. ${ }^{1}$ This slow $\beta$-sheet formation is based on the driving force of only intermolecular hydrophobic interactions, while our $\beta$ sheet structure is formed rapidly by hydrophobic and electrostatic interactions other than conventional $\beta$-sheet hydrogen bondings. Rapid $\beta$-sheet formation may be also responsible for the intramolecular event.

The most likely explanation is that these polypeptides have high $\beta$-sheet forming potential and stability. There are two types of side chain interactions in addition to conventional $\beta$-sheet hydrogen bondings. One is negative enthalpy interaction, ion pairs or salt bridges, and the other, entropic interaction which is hydrophobic. These intramoleculer interactions contribute to the formation of highly stable $\beta$-sheet structures.

\section{Interactions for Monomeric $\beta$-Sheet Structure Formation}

Diverse amphiphilic polypeptides are composed of alternating hydrophobic and hydrophilic amino acid residues which form bilayer $\beta$-sheet structures with a hydrophobic interior and hydrophilic exterior in aqueous solution. ${ }^{1}$ It is difficult to find interactions other than hydrophobic interactions between $\beta$-sheets stabilize the bilayer $\beta$-sheet structures for amphiphilic polypeptides such as poly(Val-Lys), poly(Leu-Lys), poly(Phe-Lys), poly(Leu-Glu). However, in the case of our polypeptides, there may be three intramolecular interactions between side chains other than conventional $\beta$-sheet hydrogen bondings for stabilizing the $\beta$-sheet structure because the polypeptide is presumed to exist as monomeric $\beta$-sheet 
structure from the agreement of molecular weight. Figure 10 illustrates intramolecular hydrophobic and electrostatic interactions on the side chains of the polypeptides. There would be hydrophobic interactions between the $\beta$-sheets for promoting stability. The hydrophobic domain composed of several hydrophobic amino acid residues on each side of the $\beta$-sheet interact with the domain of an adjacent $\beta$-sheet as illustrated in Figure 10. Secondly, electrostatic interactions between lysine and glutamic acid residues within the $\beta$-sheet may stabilize the single $\beta$-sheet itself. Finally, it would be possible to form electrostatic interactions between lysine residues on one $\beta$-sheet and glutamic acid residues on a neighboring $\beta$-sheet at low ionic strength as illustrated in Figure 10. There would also be intramolecular conventional $\beta$-sheet hydrogen bondings between $\beta$ strands. Each polypeptide would fold by electrostatic interactions as well as hydrophobic interactions in addition to interstrand conventional $\beta$-sheet hydrogen bondings.

Consequently, it is likely that poly(Glu-Val-Lys-Val) and poly(Glu-Leu-Lys-Leu) form monomeric $\beta$-sheet

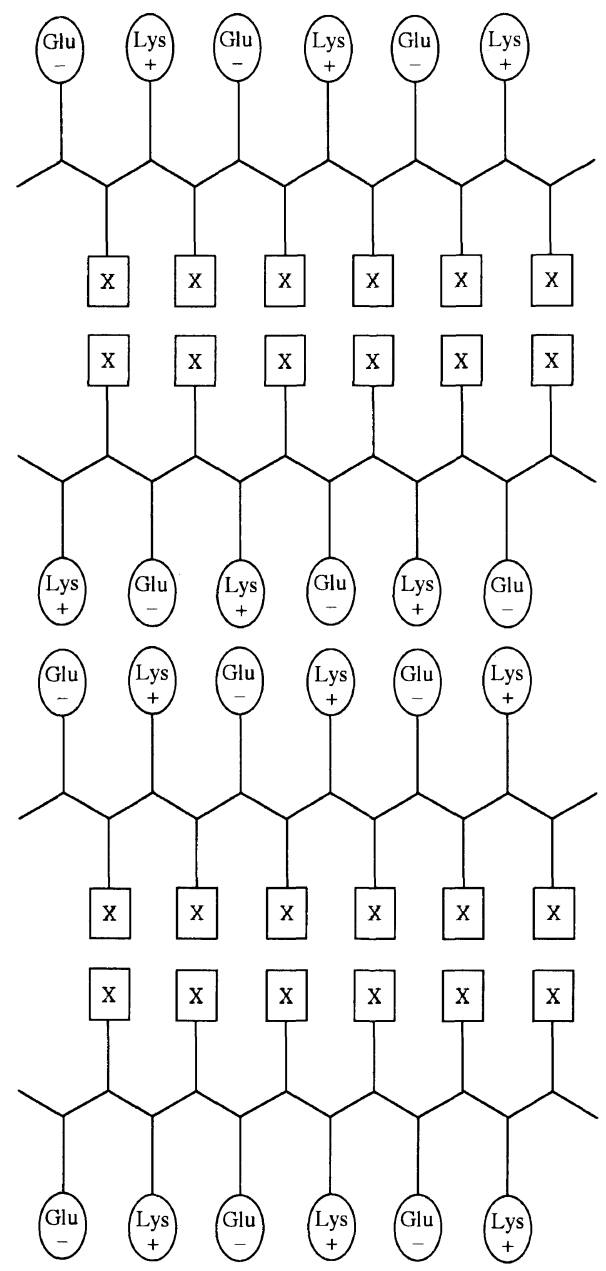

Figure 10. Schematic model of the intersheet side chain interactions of the monomeric $\beta$-sheet structure. X, Val or Leu. structures which several $\beta$-sheets are assembled by the intersheet interactions, as illustrated in Figure 10. Monomeric $\beta$-sheet structures may be formed by folding the $\beta$-sheets by hydrophobic interactions and electrostatic interactions in addition to conventional $\beta$-sheet hydrogen bondings.

These experiments show that it is feasible to study side chain interactions involving charged residues and hydrophobic residues in two designed alternating amphiphilic polypeptides. The mechanism of $\beta$-sheet formation and monomeric $\beta$-sheet structures is not understood completely. These highly stable $\beta$-sheet forming polypeptides should provide good models for testing hydrophobic and electrostatic interactions in proteins as well as constructing de novo designed proteins and peptides involving $\beta$-sheet structures. The polypeptides may be also good models for studying the mechanism of the folding of natural $\beta$-proteins because the polypeptides fold themselves to form the monomeric $\beta$-sheet structures.

Acknowledgments. I thank Dr. M. Hirami of Unitika Ltd. for many helpful comments on this work.

\section{REFERENCES}

1. A. Brack and L. E. Orgel, Nature, 256, 383 (1975).

2. W. B. Rippon, H. H. Chen, and A. G. Walton, J. Mol. Biol., 75, 369 (1973).

3. S. L. Kielland, L. A. Slotin, and R. E. Williams, Can. J. Chem., 56, 2657 (1978)

4. Y. Trudelle, Polymer, 16, 9 (1975).

5. S. Saint-Pierre, R. T. Ingwall, M. S. Verlander, and M. Goodman, Biopolymers, 17, 1837 (1978).

6. G. Seipke, H. A. Arfmann, and K. G. Wagner, Biopolymers, 13, 1621 (1974).

7. A. Brack and G. Spach, J. Am. Chem. Soc., 103, 6319 (1981).

8. D. G. Osterman and E. T. Kaiser, J. Cell. Biochem., 29, 57 (1985).

9. D. Osterman, R. Mora, F. J. Kezdy, E. T. Kaiser, and S. C. Meredith, J. Am. Chem. Soc., 106, 6845 (1984).

10. S. Zhang, C. Lockshin, R. Cook, and A. Rich, Biopolymers, 34, 663 (1994).

11. S. Marqusee and R. L. Baldwin, Proc. Natl. Acad. Sci. U.S.A., 84, 8898 (1987)

12. P. Y. Chou and G. D. Fasman, Biochemistry, 13, 222 (1974).

13. P. Doty, J. H. Bradbury, and A. M. Holtzer, J. Am. Chem. Soc., 78, 947 (1956).

14. T. Takakura, T. Konno, and H. Meguro, Anal. Sci., 1, 215(1985).

15. N. Greenfield and G. D. Fasman, Biochemistry, 8, 4108 (1969)

16. K. Nakajima and K. Okawa, Bull. Chem. Soc. Jpn., 46, 1811 (1973).

17. A. Yaron, N. Tal, and A. Berger, Biopolymers, 11, 2461 (1972).

18. M. Fujino, M. Wakimasu, S. Shinagawa, C. Kitada, and H. Yajima, Chem. Pharm. Bull., 26, 539 (1978).

19. S. Takahashi, Bull. Chem. Soc. Jpn., 42, 521 (1969).

20. T. Ito and S. Takahashi, Bull. Chem. Soc. Jpn., 47, 2720 (1974).

21. N. L. Benoiton and F. M. F. Chen, Can. J. Chem., 59, 384 (1981).

22. P. M. Hardy, H. N. Rydon, and R. C. Thompson, J. Chem. Soc., Perkin Trans. 1, 5 (1972).

23. H. Morii, S. Honda, K. Ichimura, and H. Uedaira, Bull. Chem. Soc. Jpn., 64, 396 (1991).

24. M. Engel, R. W. Williams, and B. W. Erickson, Biochemistry, 30, 3161 (1991) 